\title{
Plasma Glucagon Suppression by Phenformin in Man
}

\author{
N. V. Bohannon, J. H. Karam, M. Lorenzi, J. E. Gerich, S. B. Matin, and P. H. Forsham \\ Metabolic Research Unit and Department of Medicine, University of California, San Francisco, California, USA
}

Summary. In an attempt to elucidate the mechanism of action of phenformin, eleven juvenile-onset, insulin-requiring diabetic subjects underwent four different treatment regimens during standard breakfast tests. These four treatments were: control (no insulin or phenformin); insulin alone (15 $\mathrm{U}$ regular insulin administered subcutaneously one-half hour before breakfast); phenformin alone $(50 \mathrm{mg}$ of the timed-release capsule given twice daily for three days before the study and two and one-half hours before breakfast on the day of study); and phenformin plus insulin (in the amounts and at the times stated above). Phenformin was found to decrease postprandial hyperglycaemia significantly when compared with control values, and its addition to insulin further decreased the postprandial glucose rise below that found with insulin alone $(\mathrm{p}<0.005)$. These effects were associated with a reduction in early (30-min) postprandial hyperglucagonaemia ( $p$ $<0.05$ ). Triglyceride levels, gastrin secretion, growth hormone levels, and increments of $\alpha$-amino nitrogen were not affected by phenformin. Thus, suppression of postprandial hyperglucagonaemia may be an additional mechanism in the reduction of postprandial hyperglycaemia after phenformin.

Key words: Phenformin, glucagon suppression, juvenile diabetes.

Plasma glucagon levels consistently rise within 30 minutes after a mixed meal of protein, fat and carbohydrate in insulin-deficient diabetic patients, but not in normal subjects [1]. Intestinal amino-acid absorption and gut secretion of alpha cell secretagogues (such as pancreozymin) may contribute to this hyperglucagonaemia [2-4], which in turn participates in the genesis of diabetic postprandial hyperglycaemia [1]. Reduction of postprandial hyperglucagonaemia in diabetics with somatostatin, a hypothalamic tetradecapeptide, has been associated with a reduction in postprandial hyperglycaemia $[1,5]$.

Phenformin is another agent that can reduce hyperglycaemia, even in juvenile diabetics whose beta cells are non-functional [6]. Since phenformin is reported to reduce both amino-acid absorption $[7,8]$ and gut hormone secretion [9] in man, its efficacy in reducing postprandial hyperglycaemia, as well as its effect on plasma glucagon levels, was studied in eleven insulin-dependent diabetic subjects given a standard breakfast.

\section{Subjects and methods}

\section{Subjects}

Informed consent was obtained from eleven patients with insulin-requiring diabetes mellitus. Their pertinent clinical characteristics are shown in Table 1. All had a history of ketoacidosis or hyperglycaemia with persistent ketonuria. None was acutely ill at the time of the study and all were within 10 per cent of ideal weight. Four patients showed evidence of diabetic complications: retinopathy in Patients 1 and 5, peripheral neuropathy in Patient 2, and autonomic neuropathy involving the bladder in Patient 3 . None of the eleven had evidence of cardiovascular or other associated diseases. They were taking no regular medication other than vitamin and mineral supplements. They were studied either as outpatients or were admitted to the General Clinical Research Centre at the University of California, San Francisco, two days before testing and placed on appro- 
Table 1. Clinical characteristics of diabetic subjects

\begin{tabular}{|c|c|c|c|c|c|}
\hline 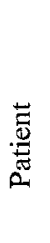 & $q_{1}^{\infty}$ & 岁 & 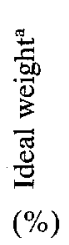 & 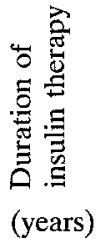 & 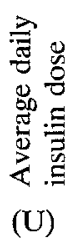 \\
\hline 1 & 27 & $\mathbf{M}$ & 99 & 14 & 60 \\
\hline 2 & 26 & $\mathrm{M}$ & 101 & 20 & 48 \\
\hline 3 & 49 & $\mathbf{M}$ & 106 & 15 & 40 \\
\hline 4 & 19 & $\mathbf{M}$ & 104 & $<1$ & 40 \\
\hline 5 & 30 & $\mathbf{M}$ & 103 & 26.5 & 50 \\
\hline 6 & 23 & $\mathbf{M}$ & 102 & 4.5 & 44 \\
\hline 7 & 50 & $\mathrm{~F}$ & 98 & 7 & 30 \\
\hline 8 & 32 & $\mathrm{~F}$ & 100 & 4 & 36 \\
\hline 9 & 28 & $\mathbf{M}$ & 100 & 4 & 34 \\
\hline 10 & 30 & $\mathbf{M}$ & 102 & 1 & 30 \\
\hline 11 & 42 & $\mathrm{~F}$ & 99 & 5 & 26 \\
\hline
\end{tabular}

a As established by Metropolitan Life Insurance Co. tables

priate weight-maintaining, American Diabetes Association diets. On the day before testing, their usual morning insulin was administered, but no long-acting insulin was given for the 18 hours preceding the breakfast test and no regular insulin during the preceding 10 hours, except under the conditions of the protocol. For this reason, baseline fasting glucose values were considerably higher than the patients' usual control levels when intermediate-acting insulin had not been excluded on the evening before.

\section{Experimental Protocol}

Studies were begun between 6 and 9 a.m. after an overnight fast.

A standard breakfast consisting of two pieces of buttered toast, $8 \mathrm{oz}$ skim milk $(240 \mathrm{ml}), 8 \mathrm{oz}$ orange juice $(240 \mathrm{ml})$, and two hard-boiled eggs (520 calories; 50 per cent carbohydrate, 30 per cent fat, and 20 per cent protein) was consumed within 15 minutes on four separate test days.

Two tests were performed without phenformin. On one occasion the breakfast alone was given (Control); on the other, $15 \mathrm{U}$ regular insulin was administered subcutaneously 30 minutes before the breakfast (Insulin Alone). Subsequently, $50 \mathrm{mg}$ phenformin (DBI-TD ${ }^{\mathrm{R}}$; Geigy Pharmaceuticals, Ardsley, New York) was administered to the patients twice daily along with their usual insulin dosage for at least two to five days before testing. $\mathrm{Du}-$ ring phenformin therapy, two more breakfast tests were carried out: 120 minutes after a $50 \mathrm{mg}$ phenformin timed-release capsule was administered be- tween 6 and 7 a.m., $15 \mathrm{U}$ regular insulin was given and the test breakfast was consumed 30 minutes later (Phenformin plus Insulin). On another day, the breakfast was consumed 150 minutes after the early morning phenformin, but without prior insulin (Phenformin Alone).

Because previous studies from this laboratory $[1,5]$ utilized $15 \mathrm{U}$ regular insulin before a similar meal study in comparable patients, this same dose was selected to keep the procedure standardized.

Blood specimens for analysis were obtained from an antecubital vein through a butterfly needle kept patent with an infusion of $0.154 \mathrm{~mol} / \mathrm{l}$ saline solution. A 30-minute equilibration period was allowed before collecting baseline samples from the venous cannulae, obtained at -60 and -30 minutes. Immediately after the -30 -minute baseline, $15 \mathrm{U}$ of single-peak regular insulin was given subcutaneously in the upper arm during the "Insulin Alone" and "Phenformin plus Insulin" studies. After the 0-minute sample, the breakfast was consumed and subsequent blood specimens were obtained at 30,60 , and 120 minutes.

\section{Determinations}

Samples were assayed for glucose, glucagon, and growth hormone levels, by methods previously described $[5,10]$. The Unger antiserum $30 \mathrm{~K}$ was used in the glucagon determination. Triglyceride values were determined enzymatically using the method of Bucolo and David [11] modified by Calbiochem, and gastrin determinations were made by radioimmunoassay [12]. Alpha-amino nitrogen values were determined by Bio-Science Laboratory, using the method of Goodwin [13]. Serum was assayed for phenformin using gas chromotography and chemical ionization mass spectrometry [14]. Data were plotted as increments above the pre-meal value $(\min 0)$, which was assigned a value of zero. Statistical analyses comparing the effects of various treatments on the postprandial responses above baseline levels were carried out with the use of two-sided paired $t$ tests. Results are given as mean \pm SEM.

\section{Results}

The Effect of 15 U Regular Insulin on Responses to a Standard Breakfast in Diabetics (Fig. 1 and Table 2)

In eleven insulin-dependent diabetic patients whose morning insulin was withheld, a rapid rise of plasma glucose occurred after ingestion of the test meal, 
Table 2. Effect of phenformin on baseline glucose ${ }^{\mathrm{a}}$ and glucagon $^{\mathrm{b}}$ values

\begin{tabular}{|c|c|c|c|c|c|c|c|c|}
\hline \multirow[b]{3}{*}{ Patient } & \multicolumn{4}{|c|}{ Without Phenformin } & \multicolumn{4}{|c|}{ With Phenformin } \\
\hline & \multicolumn{2}{|l|}{ Control } & \multicolumn{2}{|c|}{ Insulin Alone } & \multicolumn{2}{|c|}{ Phenformin Alone } & \multicolumn{2}{|c|}{ Phen. + Ins. } \\
\hline & Glucose & Glucagon & Glucose & Glucagon & Gluçose & Glucagon & Glucose & Glucagon \\
\hline 1 & 238 & 70 & 317 & 72 & 327 & 113 & 283 & 77 \\
\hline 2 & 261 & 168 & 200 & 183 & 144 & 133 & 138 & 150 \\
\hline 3 & 491 & 118 & 304 & 75 & 288 & 44 & 286 & 60 \\
\hline 4 & 153 & 103 & 277 & 123 & 136 & 34 & 126 & 70 \\
\hline 5 & 330 & 115 & 295 & 63 & 318 & 49 & 400 & 72 \\
\hline 6 & 295 & 162 & 116 & 128 & 254 & 84 & 221 & 47 \\
\hline 7 & 332 & 9 & 224 & 37 & 365 & 12 & 145 & 27 \\
\hline 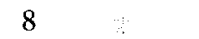 & 273 & c & 146 & c & 267 & $c$ & 319 & $\mathrm{c}$ \\
\hline 9 & 252 & 58 & 275 & 47 & 250 & 18 & 274 & 23 \\
\hline 10 & 174 & 27 & 204 & 25 & 194 & 23 & 142 & 24 \\
\hline 11 & 222 & 20 & 245 & 40 & 288 & 40 & 175 & 37 \\
\hline Mean \pm SEM & $274 \pm 28$ & $85 \pm 18$ & $236 \pm 19$ & $79 \pm 15$ & $257 \pm 22$ & $55 \pm 13$ & $228 \pm 27$ & $58 \pm 12$ \\
\hline
\end{tabular}

a $\mathrm{mg} / 100 \mathrm{ml}$

b $\mathrm{pg} / \mathrm{ml}$; mean of two values for each study

c excludes Patient 8 because substances in her sera interfered with estimation of 3485 mol. wt. glucagon

from a fasting level of $274 \pm 28 \mathrm{mg} / 100 \mathrm{ml}$ to an average increment of $79 \mathrm{mg} / 100 \mathrm{ml}$ above baseline at 30 minutes and a progressive rise to an increment of $150 \pm 32 \mathrm{mg} / 100 \mathrm{ml}$ by 2 hours (Fig. 1).

When $15 \mathrm{U}$ regular insulin was injected $30 \mathrm{~min}$ utes before meal ingestion, postprandial hyperglycaemia was reduced. Mean plasma glucose rose only $19 \mathrm{mg} / 100 \mathrm{ml}$ at 30 minutes over the baseline value of $236 \pm 19 \mathrm{mg} / 100 \mathrm{ml}$ and sustained an average peak increment of only $45 \mathrm{mg} / 100 \mathrm{ml}$ at 60 and 120 minutes. The rise in postprandial plasma $\alpha$-amino nitrogen levels was diminished significantly ( $\mathrm{p}<0.05$ when compared with the control value [Fig. 2]) only at 30 minutes after insulin administration.

Baseline plasma glucagon levels were $85 \pm 18$ $\mathrm{pg} / \mathrm{ml}$ on the day the breakfast alone was administered and $79 \pm 15 \mathrm{pg} / \mathrm{ml}$ on the day insulin was given before the meal. Plasma glucagon rises after meal ingestion were significantly reduced at all points after the administration of insulin. Without insulin pretreatment, a rapid and sustained rise of plasma glucagon reached mean peak increments of $100 \mathrm{pg} / \mathrm{ml}$ as early as 30 minutes after the meal (Fig. 1); with insulin administration, the rise in plasma glucagon was reduced by more than half and was significantly less at 30,60 , and 120 minutes $(\mathrm{p}$ $<0.005)$. Postprandial rises in plasma gastrin were reduced considerably after insulin therapy. Serum growth hormone responses were unaffected by prior insulin injection over the two-hour postprandial period.

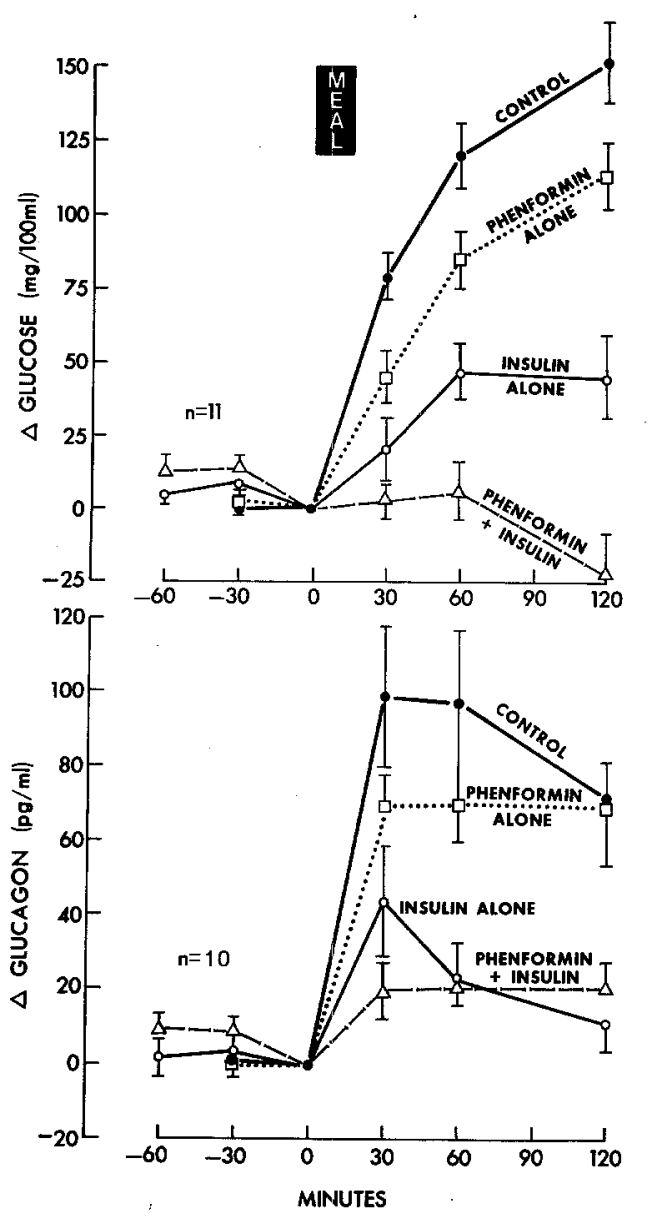

Fig. 1. Effects of therapy on glucose and glucagon responses after a standard meal in juvenile-type, insulin-requiring diabetics 


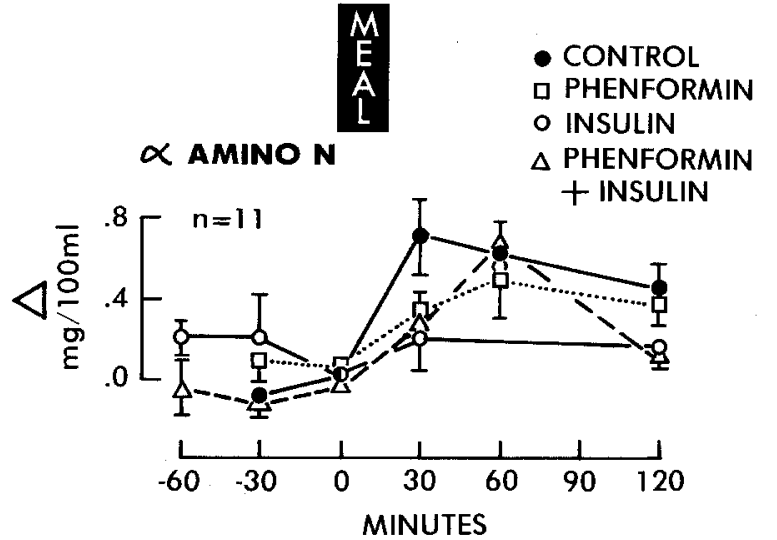

Fig. 2. Effects of therapy on $\alpha$-amino nitrogen responses after a standard meal in juvenile-type, insulin-requiring diabetics

\section{The Effect of Phenformin Therapy on Responses to the Standard Breakfast (Table 2)}

After at least two days of treatment with the 50-mg timed-release phenformin capsule b.i.d. in addition to the usual insulin replacement, two meal studies were performed. The mean serum phenformin level 1.5-4 hours after the last phenformin administration was $66 \pm 7.7 \mathrm{ng} / \mathrm{ml}$ and individual levels showed little variation throughout the meal study.

Baseline plasma glucose levels were essentially unchanged after phenformin had been added to the insulin regimen for at least two days, averaging 257 $\pm 22 \mathrm{mg} / 100 \mathrm{ml}$ as compared with the levels of 255 $\pm 17 \mathrm{mg} / 100 \mathrm{ml}$ during daily maintenance on insulin alone. This latter value represents the mean of baseline glucose concentrations for both the Control breakfast morning $(274 \pm 28 \mathrm{mg} / 100 \mathrm{ml})$ and the morning of the test in which Insulin Alone was to be administered to the same eleven subjects $(236 \pm 19$ $\mathrm{mg} / 100 \mathrm{ml}$ ). Plasma glucagon levels were significantly reduced $(p<0.02)$ in the baseline state after two to five days of phenformin therapy, averaging 55 and $58 \mathrm{pg} / \mathrm{ml}$ on two separate test days during phenformin compared with mean baseline values of 85 and $79 \mathrm{pg} / \mathrm{ml}$ before addition of phenformin to the daily regimen (Table 2). Despite this baseline lowering of plasma glucagon concentration during phenformin therapy, there was no corresponding reduction in mean basal glucose levels.

Phenformin Alone (Fig. 1). On the morning of a breakfast test in which phenformin was given but insulin was withheld, the incremental glucose rise postprandially was significantly lower: i. e., a mean two-hour increment of only $112 \mathrm{mg} / 100 \mathrm{ml}$, as opposed to $150 \mathrm{mg} / 100 \mathrm{ml}$ on a prior control day when no pre-breakfast medication was given. The early postprandial rise of glucagon was significantly blunted 30 minutes after breakfast $(p<0.05)$ when phenformin had been administered (compared with the control value). Alpha-amino nitrogen rises after the meal were not significantly different.

Phenformin Plus Insulin (Fig. 1). When $15 \mathrm{U}$ regular insulin was given 30 minutes before a meal during a period of associated phenformin treatment, there was a noteworthy flattening of the postprandial glucose response when compared with both the control study and the "Insulin Alone" procedure. Under these latter circumstances (i. e. "Insulin Alone"), the sustained incremental rise in glucose of 45 $\mathrm{mg} / 100 \mathrm{ml}$ at 1 and 2 hours was abolished when phenformin was added. A reduced $\alpha$-amino nitrogen response was noted two hours postprandially, as compared with the control value $(\mathrm{p}<0.05)$.

Associated with this abolition of postprandial hyperglycaemia was a marked reduction below control values of plasma glucagon increments after the breakfast. The 30-minute increments of plasma glucagon averaged $100 \mathrm{pg} / \mathrm{ml}$ when prior medication was withheld, and this fell to a mean increment of only $20 \mathrm{pg} / \mathrm{ml} 30$ minutes after the meal with both phenformin and insulin pre-treatment $(\mathrm{p}<0.001)$. When insulin alone was given, a mean glucagon increment of twice that found with insulin plus phenformin was noted $(\mathrm{p}<0.05)$.

Phenformin therapy did not significantly affect the baseline or postprandial values for triglycerides, gastrin, or growth hormone.

\section{Discussion}

The mechanisms proposed to explain the hypoglycaemic effect of phenformin in diabetes include: 1) the facilitation of peripheral glucose uptake [15];2) the direct inhibition of hepatic glucose production [16]; and 3) the retardation of glucose absorption from the gastrointestinal tract, either by slowing gastric emptying [17] or by directly inhibiting intestinal transport mechanisms involved in absorption [18]. The present study focuses on yet another possible hypoglycaemic mechanism of phenformin in which both basal and postprandial glucagon levels are suppressed during therapy with this drug. In diabetic patients, basal glucagon levels probably help maintain postabsorptive levels of plasma glucose by promoting hepatic glucose production in opposition to insulin's inhibitory effect. Recent support for this concept is based on the demonstration that somatostatin, a potent inhibitor of glucagon secretion, distinctly reduces basal levels of plasma glucose $[5,19]$ 
as well as lowering hepatic glucose production [19]. The role of postprandial glucagon elevations is less extensively studied; however, it has been clearly established that, whereas non-diabetic control subjects show little if any rise in plasma glucagon in the first 60 minutes after ingesting a standard breakfast, insulin-requiring diabetics show a rapid rise in plasma glucagon within 30 minutes of eating the same type of meal [1]. This early hyperglucagonaemic response in diabetics was observed in the present study and may contribute to the postprandial hyperglycaemia by interfering with hepatic uptake of ingested carbohydrates as well as by directly promoting an increased hepatic glucose output. Whereas insulin administration reduces this early postprandial hyperglucagonaemia, the combination of phenformin and insulin therapy provides the greatest reduction in the early glucagon response to a meal and is associated with virtually no postprandial hyperglycaemia.

The mechanism by which glucagon levels are reduced by phenformin remains speculative. Little is known regarding the regulation of basal glucagon levels. Possible stimuli include neurogenic factors as well as circulating catecholamines or amino acids. As regards postprandial control of pancreatic glucagon release, opposing factors include inhibition by plasma glucose and insulin elevations and stimulation by a variety of factors, including neurogenic impulses, absorbed amino acids, and release of pancreozymin or other pancreatic alpha-cell secretagogues.

Although phenformin has been previously reported to interfere with absorption of amino acids $[7,8]$, in this present investigation the combination of phenformin plus insulin does not seem to reduce plasma $\alpha$-amino nitrogen to any greater degree than insulin alone. Thus, the significantly suppressed postprandial hyperglucagonaemia after the combined therapy is probably not a consequence of reduced amino-acid absorption. A more likely explanation is the possible interference with enterocytic release of hormones such as pancreozymin by the high local concentration of phenformin within intestinal cells. Although this possibility cannot be confirmed because of the lack of an available assay for pancreozymin, it is compatible with the report of Czyzyk et al. [9], who found that secretin-mediated responses (including insulin release) were impaired after intestinal instillation of hydrochloric acid in phenformin-treated patients. Czyzyk and coworkers reported no significant effect of phenformin on plasma pancreatic glucagon levels in mild adult-onset diabetics given intraduodenal infusions of glucose or amino acids [20]. On the other hand, Berger and coworkers suggest that dimethylbiguanide potentiates the stimulatory effect of intravenous arginine on plasma glucagon levels in normal subjects [21]. Since these reports differ in the types of subjects studied, the manner in which their glucagon levels were stimulated, and, in one study [21], the nature of the biguanide used, it is difficult to compare their findings with ours.

The current findings establish that a significant improvement in postprandial hyperglycaemia occurs when phenformin is added to supplement the insulin therapy of insulin-requiring diabetics and that this reduction is also associated with a significant lessening of postprandial glucagon levels. These observations are compatible with certain clinical reports that insulin requirements are lessened $[22,23]$ and control of brittle diabetes is more stable [24] when phenformin is combined with insulin in the treatment of insulin-requiring diabetics. Not all workers, however, have observed an insulin-sparing or stabilizing effect of phenformin in juvenile diabetics [25, 26]. In addition, reports of increased cardiovascular risk with longterm phenformin use in adult-onset diabetics [27] as well as increased frequency of reports of phenformin-associated lactic acidosis raise questions as to the safety of this drug in insulin-requiring diabetes $[28,29]$.

While the present observations are of pharmacological interest and suggest a previously unsuspected mechanism for phenformin's hypoglycaemic effect, their clinical application depends upon careful evaluation of the potential risk of phenformin therapy in those brittle diabetics who might benefit from glucagon suppression as an adjunct to insulin therapy.

Acknowledgements. This work was supported in part by grant AM-12763 (05) from the National Institutes of Health and by grants from the Levi J. and Mary C. Skaggs Foundation of Oakland, California, and the Susan Greenwall Foundation of New York City. N. V.B. was the recipient of the Dorothy Frank Research Fellowship of the San Francisco Chapter of the American Diabetes Association.

\section{References}

1. Gerich, J. E., Lorenzi, M., Karam, J.H., Schneider, V., Forsham, P.H.: Abnormal pancreatic glucagon secretion and postprandial hyperglycaemia in diabetes mellitus. J. A. M. A. 234, 159-165 (1975)

2. Rocha, D.M., Faloona, G. R., Unger, R. H.: Glucagon-stimulating activity of 20 amino acids in dogs. J. Clin. Invest. 51, 2346-2351 (1972)

3. Unger, R. H., Ketterer, H., Dupre, J., Eisentraut, A. M.: The effects of secretin, pancreozymin, and gastrin on insulin and glucagon secretion in anesthetized dogs. J. Clin. Invest. 46, 630-645 (1967) 
4. Unger, R.H.: Glucagon physiology and pathophysiology. N. Engl. J. Med. 285, 443-449 (1971)

5. Gerich, J.E., Lorenzi, M., Schneider, V., Karam, J. H., Rivier J., Guillemin, R., Forsham, P. H.: Effects of somatostatin on plasma glucose and ghucagon levels in human diabetes mellitus: pathophysiologic and therapeutic implications. $N$. Engl. J. Med. 291, 544-547 (1974)

6. Davidoff, F.: Guanidine derivatives in medicine. N. Engl. J. Med. 289, 141-146 (1973)

7. Caspary, W.F., Creutzfeldt, W.: Inhibition of intestinal amino acid transport by blood sugar lowering biguanides. Diabetologia 9, 6-12 (1973)

8. Czyzyk, A., Lawecki, J., Rogala, H., Malczewski, B.: Effect of biguanides on the intestinal absorption of amino acids. In: R.R. Rodriguez, J. Vallance-Owen (Eds.): Diabetes: Proceedings of the Seventh Congress of the International Diabetes Federation, pp. 720-725. Amsterdam: Excerpta Medica 1971

9. Czyzyk, A., Szadkowski, M., Rogala, H., Lawecki, J.: Effect of phenformin on the exocrine function of the pancreas and on insulin secretion after intraduodenal infusion of $\mathrm{HCl}$ and intravenous injection of secretin. Diabetes 22, 932-937 (1973)

10. Unger, R., Eisentraut, A.: Glucagon. In: C. Grey (Ed.): Hormones in blood, Vol. 1, 2nd ed., pp. 83-128. New York: Academic Press 1968

11. Bucolo, G., David, H.: Quantitative determination of serum triglycerides by the use of enzymes. Clin. Chem. 19, 476-482 (1973)

12. Yalow, R.S., Berson, S.A.: Radioimmunoassay of gastrin. Gastroenterology 58, 1-14 (1970)

13. Goodwin, J.F.: The colorimetric estimation of plasma amino nitrogen with DNFB. Clin. Chem. 14, 1080-1090 (1968)

14. Matin, S. B., Karam, J.H., Forsham, P.H., Knight, J. B.: Determination of phenformin in biological fluids using chemical ionization mass spectrometry. Biomed. Mass Spectrom 1, 320-322 (1974)

15. Williams, R.H., Tyberghein, J.M., Hyde, P.M., Nielsen, R. L.: Studies related to the hypoglycemic action of phenethyldiguanide. Metabolism 6, 311-319 (1957)

16. Söling, H.-D.: The effects of blood glucose lowering biguanides on liver metabolism. Acta Diabetol. Lat. 6 (Suppl. 1), 656-677 (1969)

17. Gomez-Perez, F. J., Ryan, J. R., Staub, R.: Influence of phenformin on gastric emptying rate. J. Clin. Pharmacol. 14 261-263 (1974)
18. Czyzyk, A., Lawecki, J., Sadowski, J., Ponikowska, I., Szczepanik, Z.: Effect of biguanides on intestinal absorption of glucose. Diabetes 17, 492-498 (1968)

19. Koerker, D. J., Ruch, W., Chideckel, E., Palmer, J., Goodner, C. J., Ensinck, J., Gale, C. C.: Somatostatin: hypothalamic inhibitor of the endocrine pancreas. Science 184, 482-484 (1974)

20. Czyzyk, A., Heding, L. G., Malczewski, B., Miedzinska, E.: The effect of phenformin upon the plasma pancreatic and gut glucagon-like immunoreactivity in diabetics. Diabetologia 11, 129-133 (1975)

21. Berger, W., Stahl, M., Ohnhaus, E., Göschke, H.: Pancreatic glucagon, plasma insulin and blood glucose responses to arginine infusion in nondiabetic subjects following biguanide pretreatment. Horm. Metab. Res. 6, 165 (1974)

22. Fabrykant, M., Ashe, B.I.: Use of long-acting phenformin (DBI-TD) with insulin in insulin-dependent diabetes. Metabolism 10, 684-688 (1961)

23. Bloom, A., Kolbe, R. J.: Phenformin in insulin-dependent diabetics. Br. Med. J. 1970 I, 660-662

24. Creutzfeldt, W., Söling, H.-D., Zarday, Z.: The combined use of insulin, tolbutamide and biguanides in the treatment of diabetes mellitus: clinical significance and experimental findings. Metabolism 12, 264-277 (1963)

25. Pirart, J.: Failure of the biguanides to improve the control of unstable diabetes treated with insulin. Diabetologia 7, 283-286 (1971)

26. Kaye, R., Davidson, M. H.: Limitations in the use of oral hypoglycemic agents in juvenile patients with diabetes. I. Pediatr. 66, 844-856 (1965)

27. The University Group Diabetes Program. A study of the effects of hypoglycemic agents on vascular complications in patients with adult-onset diabetes. V. Evaluation of phenformin therapy. Diabetes 24 (Suppl. 1), 65-184 (1975)

28. Fulop, M., Hoberman, H. D.: Phenformin-associated metabolic acidosis. Diabetes 25, 292-296 (1976)

29. Conlay, L. A., Loewenstein, J. E.: Phenformin and lactic acidosis. J. A. M. A. 235, 1575-1578 (1976)

Received: January 21, 1977, and in revised form: May 10, 1977

J.H. Karam, M.D.

Metabolic Research Unit, 1143 HSW

University of California

San Francisco, CA 94143

USA 